\title{
TESTS WITH THE CH-47A CHINOOK HELICOPTER IN SOFT CLAY SOILS
}

by

E. S. Rush

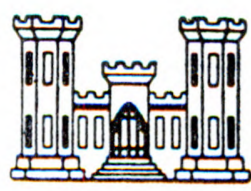

January 1966

Sponsored by

U. S. Army Materiel Command

Project No. I-V-0-2170I-A-046

Task 02

Conducted by

U. S. Army Engineer Waterways Experiment Station CORPS OF ENGINEERS

Vicksburg, Mississippi

ARMY-MRC VICKSBURG, MISS

DISTRIBUTION OF THIS DOCUMENT IS UNLIMITED 